\title{
Piecewise Linier Model Untuk Manajemen Laba: Investigasi Sebelum dan Sesudah Implementasi IFRS pada Perusahaan Manufaktur di Bursa Efek Indonesia
}

\author{
Rizki Fitrah Ramadhani', Nurmala Ahmar ${ }^{2}$, Nuraini Rokhmania ${ }^{3}$ \\ ${ }^{1,2,3}$ STIE Perbanas Surabaya, Jalan Nginden Semolo 34-36 Surabaya 60118. Indonesia.
}

I N F O A R T I K E L

JEL Classification:

G14

Keywords:

earning management, accrual earning management, implementation of IFRS, piecewise linear model.

\section{A $B$ S $S$ T $R$ A $A$ C $T$}

This study aimed to examine differences in accrual earnings management by using piecewise linear model of approaching the companies listed on the Indonesian Stock Exchange (BEI) before and after the implementation of IFRS. Samples are 108 manufacturing companies. Year study was conducted during the period 2011 to calculate before the implementation of IFRS and 2013 to calculate after the implementation of IFRS. Criteria in the selection of the research object, among others, the company that serves the complete financial statements, the company does not move the sector, does not cease trading companies, as well as companies that serve the financial statements with the currency. The research proves the difference in accrual earnings management with Piecewise Linear Model approach in 2011 and in 2013.

\section{A B S T T R A K}

Penelitian ini bertujuan untuk menguji perbedaan manajemen laba akrual dengan menggunakan model piecewise linear mendekati perusahaan yang terdaftar di Bursa Efek Indonesia(BEI) sebelum dan setelah pelaksanaan IFRS. Sampel adalah 108 perusahaan manufaktur. Tahun penelitian ini dilakukan selama periode 2011 untuk menghitung sebelum pelaksanaan IFRS dan 2013 untuk menghitung setelah pelaksanaan IFRS. Kriteria dalam pemilihan objek penelitian, antara lain, perusahaan yang melayani laporan keuangan yang lengkap, perusahaan tidak bergerak sektor, tidak menghentikan perdagangan perusahaan, serta perusahaan yang melayani laporan keuangan dengan mata uang. Hasil penelitian membuktikan adanya perbedaan manajemen laba akrual dengan Piecewise Linear pendekatan Model pada tahun 2011 dan pada tahun 2013.

\section{Pendahuluan}

Akuntansi adalah sebuah sistem informasi yang digunakan untuk menyediakan berbagai keterangan mengenai data ekonomi. Informasi akuntansi yang baik harus memenuhi standar yang memadai dalam pelaporan keuangan. Perusahaan akan mengeluarkan laporan keuangan perusahaan agar perusahaan mendapatkan tambahan modal dari pihak ketiga. Angka yang ada pada laporan keuangan merupakan hal yang penting dalam membentuk opini orang-orang terhadap suatu perusahaan. Salah satu angka yang sering dilihat orang adalah angka pada pos laba bersih .Laba merupakan indikator yang dapat digunakan untuk mengukur kinerja operasional sebuah

*Email Korespondensi:1rframadhani3@gmail.com, 2nurmalaahmar@gmail.com, 3nuraini@perbanas.ac.id 
perusahaan. Dimana informasi tentang laba digunakan untuk mengukur keberhasilan atau kegagalan suatu bisnis dalam mencapai tujuan operasi yang telah ditetapkan perusahaan. Baik pihak kreditur maupun investor, menggunakan laba bersih untuk: mengevaluasi kinerja pihak manajemen, memperkirakan earnings power, dan digunakan untuk memprediksi laba perusahaan di masa yang akan datang.

Angka laba bersih yang ada pada laporan keuangan sebuah perusahaan adalah angka yang paling sering dimanipulasi oleh para manajer. Adanya perilaku pihak manajemen dalam memanipulasi laporan keuangan disebut manajemen laba (earning management). Akan tetapi, karena adanya krisis global yang terjadi beberapa tahun lalu yang disebabkan oleh kegagalan investasi properti di Amerika serta terkuaknya kecurangan - kecurangan yang dilakukan oleh perusahaan besar seperti Enron dalam memanipulasi laporan keuangan menyebabkan menurunnya kepercayaan global terhadap standar akuntansi Amerika yaitu (US GAAP). Banyak Negara di dunia kini telah beralih dari US GAAP ke standar akuntansi internasional atau biasa disebut IFRS.

IFRS berbasiskan prinsip yang meliputi penilaian profesional yang kuat dengan disclosures (pengungkapan) yang jelas dan transparan mengenai substansi ekonomis transaksi, penjelasan hinggamencapaikesimpulan tertentu, dan akuntansi terkait transaksi tersebut. Penerapan IFRS di Indonesia diperkirakan akan memberikan dampak peningkatan terhadap kualitas akuntasi seperti yang kebanyakan terjadi diNegara-negara Eropa. Melakukan implementasi IFRS akan mendapatkan beberapa manfaat tersebut antara lain meningkatkan kredibilitas dan kegunaan laporan keuangan, meningkatkan relevansi laporan keuangan serta meningkatkan transparasi keuangan. Namun, seperti yang dialami oleh Negara berkembang lainnya dalam mengimplementasikan IFRS, di Indonesia diperkirakan akan memperoleh dampak kurang siapnya infrastruktur seperti DSAK (Dewan Standar Akuntansi Keuangan) sebagai financial accounting standart setter di Indonesia, kondisi peraturan perundang-undangan yang belum tentu sinkron dengan IFRS serta kurang siapnya sumber daya manusia dan dunia pendidikan di Indonesia.

Piecewise Linear Model (PLM) adalah model pengukuran manajemen laba akrual yang mempertimbangkan akun penjualan dan return saham. Model pengukuran ini lebih cocok digunakan karena tidak banyak terjadi perubahan cara pengukran dan penilaian akun akrual, sementara implementasi IFRS secara mandatory berdampak besar pada pengukuran akun-akun yang mengandung unsure akrual. Moreira dan Pope (2007) melakukan penelitian tentang pendekatan Piecewise Linear untuk mengukur manajemen laba khususnya dalam bentuk akrual. Mengukur manajemen laba akrual dengan pendekatan Piecewise Linear dapat mengontrol adanya asimetri informasi karena adanya pengakuan pendapatan dan kerugian karena manajemen laba akrual bukan hanya dapat terjadi karena penggunaan standar akuntansi yang digunakan tetapi juga dapat terjadi karena adanya pengakuan pendapatan yang ditunda atau diakui lebih awal, begitu juga dengan beban atau kerugian. Penelitian ini menggunakan pendekatan Piecewise Linear Model yang memiliki komponen aset, revenue, dan return. Aset untuk pembobotan agar setiap perusahaan memiliki ukuran yang sama, revenue untuk menggambarkan adanya pendapatan yang diproyeksikan pada penjualan, sedangkan return menggambarkan asimetri informasi akibat adanya pengakuan pendapatan. Callao dan Jarne (2010) membandingkan diskresioneri akrual perusahaan yang listing di 11 pasar saham eropa sesaat setelah pengadopsian IFRS. Mereka menemukan bahwa IFRS mendukung diskresioneri akuntansi dan perilaku oportunistik. Wang dan Campbell (2012) yang menyatakan adopsi IFRS menurunkan manajemen laba tetapi bukti ini belum cukup kuat dan masih harus dilakukan penelitian lebih lanjut. Beberapa peneliti yang menggunakan model tersebut dalam mendeteksi praktik manajemen laba dilakukan di beberapa negara, Australia (Andersen, et al.). Hal yang sama dilakukan oleh Konstantinidi et al. (2012); 


\section{Telaah Teori Dan Pengembangan Hipotesis}

Seperti yang dikatakan oleh Jensen dan Meckling (1976) hubungan keagenan adalah sebuah kontrak antara manajemen (agent) dengan investor (principal). Pandangan agency theory adalah adanya pemisahan antara pihak principal dan agent yang menyebabkan munculnya potensi konflik yang dapat mempengaruhi kualitas laba yang dilaporkan. Teori keagenan ditekankan untuk mengatasi dua permasalahan yang dapat terjadi dalam hubungan keagenan (Einsenhard, 1989 dalam Darmawati, dkk 2004), yaitu :

1. Masalah keagenan yang timbul pada saat keinginan atau tujuan dari principal dan agent berlawanan dan merupakan hal yang sulit bagi principal untuk melakukan verifikasi tentang apa yang benar-benar dilakukan oleh agent;

2. Masalah pembagian resiko yang timbul pada saat principal dan agent memiliki sikap yang berbeda terhadap resiko. Einsenhard dalam Darmawati, dkk (2004), menyatakan bahwa adanya asumsi yang mengenai sifat dasar manusia: (a) Manusia pada umumnya mementingkan diri sendiri (self interest), (b) Manusia memiliki daya pikir terbatas mengenai persepsi manusia mendatang (bounded rationality), (c) Manusia selalu menghindari resiko (risk averse).

Adanya ketiga sifat tersebut menyebabkan informasi yang dihasilkan manusia untuk manusia lain selalu dipertanyakan reabilitasnya dan informasi yang disampaikan biasanya diterima tidak sesuai dengan kondisi perusahaan yang sebenarnya atau lebih dikenal sebagai informasi yang tidak simetris atau assymetry information (Ujiyantho \& Pramuka, 2007), sehingga hal tersebut memberikan kesempatan kepada manajer untuk melakukan manajemen laba. Manajer sebagai pengelola perusahaan lebih banyak mengetahui informasi internal dan prospek perusahaan di masa yang akan datang dibandingkan pemilik. Di samping itu, manajer berkewajiban memberikan informasi mengenai kondisi perusahaan kepada pemilik.

Ada beberapa definisi manajemen laba,
Schipper dalam Midiastuty \& Machfoedz (2003) mendefinisikan manajemen laba sebagai suatu intervensi dengan maksud tertentu terhadap proses pelaporan keuangan eksternal dengan sengaja untuk memperoleh beberapa keuntungan pribadi. Sedangkan menurut Healy dan Wahlen, manajemen laba terjadi ketika manajer menggunakan pertimbangan (judgment) dalam pelaporan keuangan dan penyusutan transaksi untuk mengubah laporan keuangan dengan tujuan untuk memanipulasi besaran (magnitude) laba kepada beberapa stakeholders tentang kinerja ekonomi perusahaan atau untuk mempengaruhi hasil perjanjian (kontrak) yang tergantung pada angka-angka akuntansi yang dilaporkan.

Terjadinya manajemen laba dikarenakan penyusunan laporan keuangan menggunakan dasar akrual. Dalam hal ini pendapatan dapat dimanipulasi melalui discretionary accruals, menjelaskan transaksi akrual bisa berwujud 1) transaksi yang bersifat nondiscretionary accruals, yaitu apabila transaksi telah dicatat dengan metode tertentu maka manajemen diharapkan konsisten dengan metode tersebut dan 2) transaksi yang bersifat discretionary accruals, yaitu metode yang memberikan kebebasan kepada manajemen untuk menentukan jumlah transaksi akrual secara fleksibel (Gumanti, 2000).Perhitungan akrual abnormal diawali dengan perhitungan total akrual.Total akrual adalah selisih antara laba dan arus kas yang berasal dari aktivitas operasi.

Sulistiawan, Januarsi dan Alvia (2011:31) mengemukakan beberapa motivasi terjadinya manajemen laba, yaitu:

\section{Bonus Purpose}

Manajer yang memiliki informasi atas laba bersih perusahaan akan bertindak secara oportunistik untuk melakukan manajemen laba dengan memaksimalkan laba saat ini.

\section{Political Motivation}

Manajemenlaba digunakan untukmengurangi laba yang dilaporkan pada perusahaan publik. Perusahaan cenderung mengurangi laba yang dilaporkan karena adanya tekanan publik yang mengakibatkan pemerintah menetapkan peraturan yang lebih ketat. 


\section{Taxation Motivation}

Motivasi penghematan pajak menjadi motivasi manajemen laba yangpaling nyata. Berbagai metode akuntansi digunakan dengan tujuanuntuk penghematan pajak pendapatan.

4. Pergantian CEO

CEO yang mendekati masa pensiun akan cenderung menaikkan pendapatan untuk meningkatkan bonus mereka. Dan jika kinerja perusahaan buruk, mereka akan memaksimalkan pendapatan agar tidak diberhentikan.

\section{Initial Public Offering ( IPO)}

Perusahaan yang akan go public belum memiliki nilai pasar, dan menyebabkan manajer perusahaan yang akan go public melakukan manajemen laba dengan harapan dapat menaikkan harga saham perusahaan.

6. Pentingnya Memberi Informasi Kepada Investor

Informasi mengenai kinerja perusahaan harus disampaikan kepada investor sehingga pelaporan laba perlu disajikan agar investor tetap menilai bahwa perusahaan tersebut dalam kinerja yang baik.

\section{Model Piecewise Linear}

Model Piecewise Linear adalah salah satu model untuk mengukur manajemen laba akrual yang dikemukakan oleh Pope dan Walker (1999); . Model Piecewise Linear dapat memperbaiki informasi manajemen laba akrual yang dihitung dengan model Jones (1991) dengan memperhitungkan revenue, return, dan memperhitungkan pengakuan pendapatan dan kerugian. Sehingga informasi manajemen laba akrual yang diukur dengan model Piecewise Linear lebih baik karena asimetri informasi terhadap pengakuan pendapatan dan kerugian pada laporan keuangan perusahaan dapat dideteksi dengan adanya komponen dividen pada return. Penelitian yang dilakukan oleh Moreira dan Pope (2007) menunjukkan bahwa model Piecewise Linear dapat mengontrol asimetris keuntungan dan kerugian. Model Piecewise Linearmempunyai formula sebagai berikut :
$T A_{t}=\beta_{1}\left(\frac{1}{A_{t-1}}\right)+\beta_{2} \Delta R E V_{t}+\beta_{3} D_{1}+\beta_{4} R E T_{t}+\beta_{5} D_{1} R E T_{t}+\varepsilon_{t} \cdot(1)$

Keterangan:

$\mathrm{TA}_{\mathrm{t}}=$ Total akrual perusahaan pada tahun $\mathrm{t}$

$\mathrm{A}_{\mathrm{t}-1}=$ Total aset perusahaan pada tahun $\mathrm{t}-1$

$\mathrm{REV}_{\mathrm{t}}=$ Penjualan perusahaan pada tahun $\mathrm{t}$

RET $_{\mathrm{t}}=$ Return perusahaan pada tahun $\mathrm{t}$

$\mathrm{D}_{1} \quad=$ Variabel dummy, $\mathrm{RET}<0 \square 1$, RET $>0 \square 0$

$\varepsilon_{\mathrm{t}} \quad=$ Term Error atau residual

\section{International Financial Reporting Standard (IFRS)}

IFRS adalah standar akuntansi internasional yang diterbitkan oleh International Accounting Standard Board (IASB). Standar akuntansi internasional ini disusun oleh empat organisasi utama dunia yaitu Badan Standar Akuntansi Internasional (IASB) Komisi Masyarakat Eropa (EC), Organisasi Internasional Pasar Modal (IOSOC), dan Federasi Akuntansi Internasional (IFAC). IFRS sendiri menganut systemfair value based dimana terdapatkewajiban dalam pencatatan pembukuan mengenai penilaian kembali keakuratan berdasarkan nilai kini atas suatu aset, liabilitas dan ekuitas. IFRS memiliki karakteristik menggunakan "Principles Base" yaitu :

(1) Lebih menekankan Interpretasi dan aplikasi atas standar sehingga harus berfokus pada penerapan prinsip tersebut. (2) Standar membutuhkan penilaian atas substansi transaksi dan evaluasi apakah presentasi akuntansi mencerminkan realitas ekonomi.

(2) Membutuhkan professional judgement pada penerapan standar akuntansi

Lembaga profesi akuntansi IAI (Ikatan Akuntan Indonesia) menetapkan bahwa Indonesia melakukan adopsi penuh IFRS pada 1 Januari 2012. Penerapan ini bertujuan agar daya informasi laporan keuangan dapat terus meningkat sehingga laporan keuangan dapat semakin mudah dipahami dan dapat dengan mudah digunakan baik bagi 
penyusun, auditor, maupun pembaca atau pengguna lain. Dalam melakukan konvergensi IFRS, terdapat dua macam strategi adopsi, yaitu big bang strategy dan gradual strategy. Big bang strategy mengadopsi penuh IFRS sekaligus, tanpa melalui tahapan-tahapan tertentu. Strategi ini digunakan oleh negara -negara maju. Sedangkan pada gradual strategy, adopsi IFRS dilakukan secara bertahap. Strategi ini digunakan oleh negara - negara berkembang seperti Indonesia Terdapat 3 tahapan dalam melakukan konvergensi IFRS di Indonesia, yaitu:

1. TahapAdopsi(2008-2011), meliputiaktivitas dimana seluruh IFRS diadopsi ke PSAK, persiapan infrastruktur yang diperlukan, dan evaluasi terhadap PSAK yang berlaku.

2. Tahap Persiapan Akhir (2011), dalam tahap ini dilakukan penyelesaian terhadap persiapan infrastruktur yang diperlukan. Selanjutnya, dilakukan penerapan secara bertahap beberapa PSAK berbasis IFRS.

3. Tahap Implementasi (2012), berhubungan dengan aktivitas penerapan PSAK IFRS secara bertahap. Kemudian dilakukan evaluasi terhadap dampak penerapan PSAK secara komprehensif.

Indonesia merupakan bagian dari IFAC (International Federation of Accountant) yang harus tunduk pada SMO (Statement Membership Obligation), salah satunya adalah dengan menggunakan IFRS sebagai accounting standard.

Lin dan Paananen (2007) meneliti perubahan pola aktivitas manajemen laba dan menyatakan bahwaIASB tidak efektifmengurangi aktivitas manajemen laba secara keseluruhan. Callao dan Jarne membandingkan diskresioneri akrual perusahaan yang listing di 11 pasar saham eropa sesaat setelah pengadopsian IFRS. Mereka menemukan bahwa IFRS mendukung diskresioneri akuntansi dan perilaku oportunistik. Penelitian Santy dkk (2012) mengenai apakah adopsi IFRS mempengaruhi manajemen laba pada perusahaan perbankan di Bursa Efek Indonesia menunjukkan bahwa adopsi IFRS tidak berpengaruh signifikan terhadap manajemen laba. Berdasarkan kerangka pemikirtan pada gambar
1, hipotesis pada penelitian ini adalah:

H1: terdapat perbedaan manajemen laba akruam berbasis Piecewise Linear Model sebeleum dibandingkan sesudah implementasi IFRS.

\section{Metode}

Penelitian ini seluruh populasinya menggunakan perusahaan manufaktur yang terdaftar di Bursa Efek Indonesia periode 20112013. Pertimbangan untuk memilih populasi perusahaan manufaktur karena perusahaan manufaktur memiliki karakteristik akrual yang hampir sama (Julia, dkk, 2005 dalam Ujiyantho dan Pramuka, 2007). Jumlah perusahaan yang terdaftar di BEI dari tahun 2011 hingga 2013. Perusahaan yang menjadi sampel dalam penelitian ini dipilih berdasarkan kritera-kriteria tertentu (purposive sampling), yaitu:

1. Perusahaan mempunyai laporan keuangan lengkap sebelum implementasi IFRS dan sesudah implementasi IFRS yaitu tahun 2011-2013,

2. Laporan keuangan menggunakan mata uang Rupiah,

3. Tidak melakukan merger atau akuisisi selama tahun penelitian,

4. Perusahaan tidak melakukan perpindahan sektor industri.

Data yang digunakan pada penelitian ini adalah jenis data sekunder yang dapat diperoleh melalui publikasi yang terdaftar di Bursa Efek Indonesia. Data-data tersebut meliputi komponen manajemen laba akrual dengan menggunakan pendekatan Piecewise Linear Model yaitu revenue, return, dan memperhitungkan pengakuan pendapatan dan kerugian. Data yang ada dalam penelitian ini didapatkan di situs yang dimiliki oleh Bursa Efek Indonesia (BEI), yaitu www.idx. co.id dan dari Indonesia Capital Market Directory (ICMD). Pada penelitian ini menggunakan metode pengumpulan data dengan cara metode dokumentasi, yaitu data diperoleh dari objek penelitian dengan melihat langsung dari laporan keuangan tahunan perusahaan manufaktur yang telah terdaftar di Bursa Efek Indonesia (BEI).

Variable dependen pada penelitian ini 


\section{Gambar 1}

\section{Kerangka Pemikiran}

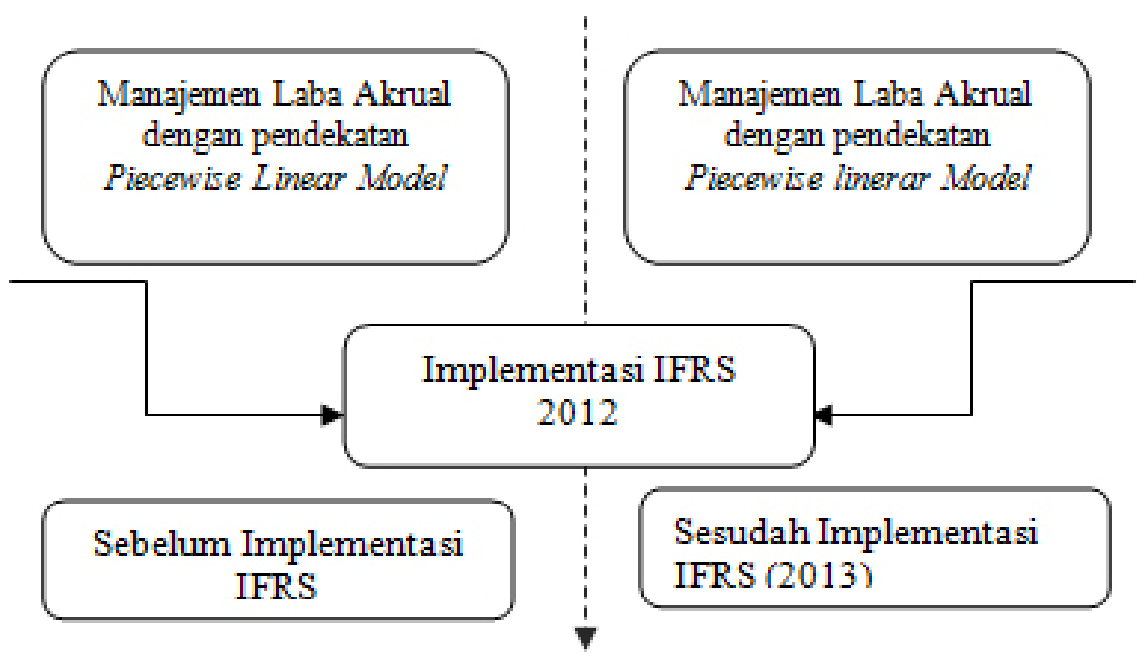

adalah manajemen laba akrual yang berfokus pada model Piecewise Linear Model. Sedangkan variabel independen dalam penelitian ini adalah implementasi sebelum dan sesudah IFRS.

\section{Definisi Operasional dan Pengukuran Variabel}

\section{Piecewise Linear Model}

$$
T A_{t}=\beta_{1}\left(\frac{1}{A_{t-1}}\right)+\beta_{2} \Delta R E V_{t}+\beta_{3} D_{1}+\beta_{4} R E T_{t}+\beta_{5} D_{1_{R E T_{t}}}+\varepsilon_{t}
$$

Keterangan :

$T A_{t}=$ Total akrual perusahaan pada tahun $\mathrm{t}$

$A_{t-1}=$ Total aset perusahaan pada tahun $\mathrm{t}-1$

$R E V_{t}=$ Penjualan perusahaan pada tahun $\mathrm{t}$

$R E T_{t}=$ Return perusahaan pada tahun $\mathrm{t}$

$D_{1}=$ Variabel dummy $R E T<0 \rightarrow 1, R E T>0 \rightarrow 0$

$\varepsilon_{t}=$ Term Error atau resial

$$
T A_{t}=N I_{t}-C F O_{t}
$$

Dimana :

$$
\begin{aligned}
& \mathrm{NI}=\text { Net Income } \\
& \mathrm{CFO}=\text { Cash Flow Operation } \\
& \mathrm{TA}=\text { Total Akrual }
\end{aligned}
$$

a. Revenue (REV) adalah nilai penjualan perusahaan di tahun tersebut. Dalam pendekatan Piecewise Linearmodel, delta revenue (REV) yang digunakan sebagai salah satu komponen pengukurnya. Untuk memenuhi komponen pengukur tersebut dibutuhkan nilai penjualan pada tahun-t $\left(\right.$ REV $\left._{t}\right)$ dan nilai penjualan pada tahun sebelumnya $\left(\mathrm{REV}_{\mathrm{t}-1}\right)$. Delta revenue (REV) diketahui melalui rumus :

$$
\Delta \mathrm{REV}=\frac{\mathrm{REV}_{\mathrm{t}}-\mathrm{REV}_{\mathrm{t}-1}}{R E V_{t-1}}
$$

b. Kemudian menentukan besarnya return (RET). Retun dapat diukur dengan menggunakan formula :

$$
R E T=\frac{C P_{t}+C P_{t-1}+D}{C P_{t-1}}
$$

Dimana :

$$
\begin{aligned}
\text { RET } & =\text { Return } \\
\mathrm{CP}_{\mathrm{t}} & =\text { Closing Price pada tahun } \mathrm{t} \\
\mathrm{CP}_{\mathrm{t}-1} & =\text { Closing Price pada tahun } \mathrm{t}-1 \\
-\quad \mathrm{D} & \text { Dividen per saham }
\end{aligned}
$$

c. Setelah semua komponen data diketahui, langkah selanjutnya adalah melakukan uji regresi data dengan persamaan sebagai berikut :

$$
T A_{t}=\beta_{1}\left(\frac{1}{A_{t-1}}\right)+\beta_{2} \Delta R E V_{t}+\beta_{3} D_{1}+\beta_{4} R E T_{t}+\beta_{5} D_{1_{R E T}}+\varepsilon_{t}
$$

Hasil dari uji regresi tersebut menunjukkan 
besarnya nilai parameter atau koefisien $(\beta)$

d. Kemudian nilai parameter yang diketahui dari regresi dimasukkan ke persamaan berikut:

$N D A_{t}=\beta_{1}\left(\frac{1}{A_{t-1}}\right)+\beta_{2} \Delta R E V_{t}+\beta_{3} D_{1}+\beta_{4} R E T_{t}+\beta_{5} D_{1-} R E T_{t}$ .......(5)

Persamaan tersebut untuk mencari nilai accrual non-diskresioner (NDA) yang kemudian nilai NDA dan TA yang telah dicari digunakan untuk menentukan besarnya akrual dengan formula;

$$
D A_{t}=N D A_{t}-T A_{t}
$$

Nilai akrual diskresioner (DA) tersebut merupakan manajemen laba akrual. Semakin besar nilai akrual diskresioner (DA) yang dihasilkan maka semakin besar perusahaan melakukan manajemen laba akrual karena daya prediksi dari revenue(REV) atau penjualan dan return(RET) diperkirakan dapat menunjukkan adanya manajemen laba akrual yang dilakukan perusahaan.

Untuk menguji apakah ada hubungan antara perbedaan antara manajemen laba akrual dengan pendekatan Piecewise Linear Model sebelum dan sesudah implementasi IFRS setelah mendapatkan nilai $\mathrm{DA}_{\mathrm{t}}$ maka digunakan model uji beda (t-test) model analisis paired sample t-test. Pengujian hipotesis dengan paired sample t-test merupakan uji beda rata-rata data berpasangan dengan menggunakan data penelitian yang terdistribusi normal.

\section{Hasil Penelitian Dan Pembahasan}

Penelitian ini menggunakan analisis statistik deskriptif, dimana jenis statistik ini melakukan analisis data populasi dengan cara mendeskripsikan atau menjelaskan data yang sudah dikumpulkan.

Tabel 1

Hasil Analisis Deskriptif

\begin{tabular}{ccc}
\hline Variabel & Mean & Std.Deviasi \\
\hline MLA2013 & -0.169 & 0.199 \\
MLA2011 & 0.311 & 0.209 \\
\hline
\end{tabular}

Berdasarkan Tabel 1 tersebut maka terlihat secara umum pada tahun 2013 nilai mean pada perusahaan manufaktur sebesar $-0,169$ nilai itu menunjukkan bahwa perusaahaan pada tahun 2013 secara umum melakukan discretionary accrual negative (menurunkan laba). Sedangkan pada tahun 2011 sebelum implementasi IFRS terlihat dari hasil uji tersebut, nilai mean sebesar 0 , ang menunjukkan bahwa pada tahun 2011 sebelum adanya implementasi IFRS perusahaanperusahaan manufaktur melakukan discretionary accrual positif (menaikkan laba).

Tabel 2

Status Manajemen Laba

\begin{tabular}{clcc}
\hline Tahun & \multicolumn{1}{c}{ Status } & Jumlah & Persentase \\
\hline \multirow{2}{*}{2011} & $\begin{array}{l}\text { DA negatif } \\
\text { (menurunkan }\end{array}$ & 2 & 3.7 \\
& $\begin{array}{l}\text { laba) } \\
\text { DA positif(me- } \\
\text { naikan laba) }\end{array}$ & 52 & 93.3 \\
& $\begin{array}{l}\text { DA negatif } \\
\text { (menurunkan }\end{array}$ & 48 & 88.9 \\
laba) & & \\
& $\begin{array}{l}\text { DA positif (me- } \\
\text { naikan laba) }\end{array}$ & 6 & 11.1 \\
\hline
\end{tabular}

Hasil pengujian yang pada tabel 2, menunjukan bahwa perusahaan pada tahun 2011 sebelum adanya implementasi IFRS yang melakukan discretionary accrual negative atau menurunkan laba adalah sebanyak 2 perusahaan dari 54 perusahaan yang diuji, dan sisanya melakukan discretionary accrual positif atau menaikkan laba. Dan pada tahun 2013 terjadi perbedaan dari tahun 2011, jika pada tahun 2011 lebih banyak perusahaan yang melakukan discretionary accrual positif atau menaikkan laba, tidak dengan tahun 2013. Pada tahun 2013 perusahaan lebih banyak melakukan discretionary accrual negative atau menurunkan laba, ada 48 perusahaan yang melakukan discretionary accrual negative, dan sisanya sebanyak 6 perusahaan melakukan discretionary accrual positif.

Penelitian ini menguji sebanyak 179 perusahaan perusahaan manufaktur tersaring menjadi 54 perusahaan yang memenuhi kriteria yang sesuai dengan tujuan penelitian. Pengukuran 
pendekatan Piecewise Linear Model diketahui dengan melakukan uji regresi pada program SPSS. Pengujian regresi ini menghitung nilai total akrua dengan cara memasukkan total asset pada tahun $\mathrm{t}-1$, penjualan pada tahun $\mathrm{t}$, return perusahaan pada tahun $t$, dan adanya variable dummy. Dari hasil pengujian diatas maka didapatkan nilai Non-Discretioner Akrual (NDA). Nilai NonDiscretioner Akrual (NDA) digunakan untuk mencari nilai Diskresioner akrual. Diskresioner akrual adalah angka yang menunjukkan besarnya manajemen laba akrual yang dilakukan dengan pendekatan Piecewise Linear Model

Tabel 3

Hasil Pengujian

\begin{tabular}{lll}
\hline Variabel & t-hitung & Signifikansi \\
\hline MLA2013-MLA2011 & -12.629 & $\mathbf{0 . 0 0 0}$ \\
\hline
\end{tabular}

Berdasarkan hasil pengujian menggunakan pendeketan Piecewise Linear Model, terbukti adanya perbedaan manajemen laba akrual dengan pendekatan Piecewise Linear Model pada tahun 2011 dan tahun 2013.Hasil pengujian diatas menunjukkan bahwa setelah adanya implementasi IFRS, perusahaan pada tahun 2011 yang sebelumnya lebih banyak melakukan income increasing berbanding terbalik pada tahun 2013 yaitu perusahaan lebih banyak melakukan income decreasing berdasarkan data yang dianalisis.

Penelitian ini mendukung hasil penelitian sebelumnya yaitu Moreira dan Pope (2007), dimana hasil penelitian mereka menyatakan adanya upaya pengendalian pengakuan asimetris keuntungan dan kerugian pada pemberlakuan manajemen laba dengan menggunakan model akrual.

\section{Simpulan, Keterbatasan dan Implikasi Hasil Penelitian}

Perusahaan mengeluarkan laporan keuangan merupakan sesuatu yang sangat penting karena dengan adanya laporan keuangan, perusahaan dapat melaporkan kinerja perusahaannya dalam satu periode. Laporan keuangan dapat dijadikan sebagai evaluasi untuk pihak internal maupun pihak eksternal. Tentunya laporan keuangan harus dapat mencerminkan keadaan perusahaan dengan sebenarnya, akan tetapi karena adanya praktek earning management ada banyak laporan keuangan yang tidak mencerminkan keadaan perusahaan yang sebenarnya. Terjadinya praktek earning management karena adanya asimetri antara pemilik dan pihak manajemen perusahaan. Dilakukannya penelitian ini bertujuan untuk dapat mengetahui bagaimana manajemen laba akrual yang terjadi pada perusahaan manufaktur di Bursa Efek Indonesia.

Dari hasil pengujian disimpulkan setelah adanya pengimplementasian IFRS, perusahaan pada tahun 2011 yang sebelumnya lebih banyak melakukan income increasing berbanding terbalik pada tahun 2013 yaitu perusahaan lebih banyak melakukan income decreasing. Mengukur manajemen laba akrual dengan pendekatan Piecewise Linear model mengindikasikan bahwa seluruh perusahaan manufaktur dalam semua sektor melakukan manajemen laba akrual baik dengan pola peningkatan laba (income increasing) maupun dengan penurunan laba (income decreasing).

Penelitian ini mempunyai keterbatasan (1) menggunakan perusahaan manufaktur yang telah terdaftar di Bursa Efek Indonesia sebagai objek penelitian.(2) Objek dari penelitian ini memiliki kriteria yang sebelumnya telah ditentukan, sehingga tidak semua perusahaan manufaktur yang terdapat di Bursa Efek Indonesia dapat menjadi objek penelitian ini. Sehingga hasil dari penelitian ini kurang mencerminkan keadaan yang sebenarnya. Berdasarkan pada hasil penelitian serta keterbatasan penelitian, maka saran-saran untuk peneliti berikutnya antara lain : (1) Mencari data penelitian yang lebih lengkap, sehingga semua perusahaan yang diteliti lebih banyak dan dapat mencerminkan keadaan yang terjadi sebenarnya, (2) Melakukan penelitian pada sektor perusahaan lainnya yang terdapat di Bursa Efek Indonesia.

\section{Daftar Pustaka}


Callao, S., Jarne, J.I., dan Lainez, J.A. (2007). Adoption of IFRS in Spain: Effect on the comparability and relevance of financial reporting. Journal of International Accounting, Auditing and Taxation, 16(2), 148-178.

Gumanti, T. A. (2000). Earnings Management: Suatu Telaat Pustaka. Jurnal Akuntansi dan Keuangan, 2, 104-115.

Jensen, Michael C. dan W.H. Meckling. (1976). Theory of The Firm: Managerial Behavior, Agency Cost and Ownership Structure. Journal of Financial Economics 3. hal. 305360.

Lin, H., Paananen, M. (2007). The Development of Value Relevance of IAS and IFRS over Time: The Case of Germany.Working Paper.

Midiastuty, Pranata P., dan Mas'ud Machfoedz. 2003. Analisa Hubungan Mekanisme Good Corporate Governance dan Indikasi Manajemen Laba. Simposioum Nasional Akuntansi VI, Surabaya, 16-17 Oktober, 2003, hal: 176-186.

Moreira, J. A., \& Pope, P. (2007). Piecewise Linear Accrual Models : do they really control for the asymmetric recognition of gains and losses?. Universidade De Porto, Faculdade de Economia de Parto.

Santy, Prima , Tawakkal \& Grace T. Pontoh. Pengaruh Adopsi IFRS Terhadap Manajemen Laba Pada Perusahaan Perbankan Di Bursa Efek Indonesia. Fakultas Ekonomi, Universitas Hasanuddin. Makassar. 